\title{
REPRESENTAÇÕES DISSONANTES DE UM ACADÊMICO BRASILEIRO SOBRE A AMÉRICA LATINA
}

\author{
Priscila Ribeiro Dorella \\ Doutoranda em História da América - FFCH/UFMG. Apoio Fapemig.
}

\begin{abstract}
Resumo
Este artigo apresenta análises das interpretações construídas sobre a América Latina por Silvio Julio de Albuquerque Lima (1895-1984), um precursor dos estudos acadêmicos sobre a América hispânica no Brasil. Seus escritos testemunham uma militância passional e, muitas vezes, agressiva em prol do mútuo conhecimento entre os países latino-americanos. Esse aspecto contribuiu para fazer dele um intelectual dissonante entre seus contemporâneos, tanto do ponto de vista da sociabilidade e das posições ideológicas defendidas, quanto das temáticas trabalhadas.
\end{abstract}

\section{Pallavras-chave}

América Latina • intelectuais • historiografia.

\section{Abstract}

This article presents a partial analysis of the interpretations built about Latin American by Silvio Julio de Albuquerque Lima, an academic pioneer of Spanish American studies in Brazil. His written work testifies a passionate and, at times, agressive militancy towards mutual knowledge between Latin American countries. This aspect has contributed to making him an outstanding intellectual amongst his contemporaries, from the perspective of sociality and his defended ideological positions, as well as the themes involved.

\section{Keywords}

Latin American • intellectuals • historiography. 
O presente artigo trata acerca do pernambucano Silvio Julio de Albuquerque Lima (1895-1984), um dos primeiros acadêmicos brasileiros a se dedicar, sistematicamente, a estudos sobre a América hispânica. Esse intelectual atuou como historiador, professor, ensaísta, jornalista, filólogo, poeta e contista, publicando, ao longo da sua vida, quase 40 livros sobre história, literatura e folclore na América Latina.

Lecionou durante muitos anos na Universidade do Brasil (atual UFRJ), no Rio de Janeiro, ocupando a cátedra de História da América e mantendo vínculo com algumas das mais importantes universidades hispanoamericanas, entre elas a Universidad Mayor de San Marcos, no Peru, na qual lecionou de 1960 a 1973, beneficiando-a com a doação voluntária de toda a sua biblioteca. Somando-se a isso, orientou, entre outras, a primeira tese de doutorado em história, defendida por uma mulher, no Brasil, a historiadora Eulália Lobo, especialista em História hispano-americana.

No entanto, Silvio Julio é, atualmente, um autor desconhecido no Brasil. Suas obras, desde 1915 até 1983 (primeira e última publicações), praticamente não foram reeditadas e não são indicadas como referência para a compreensão dos estudos latino-americanos no país. Além disso, não existia, até pouco tempo, pesquisas acadêmicas sobre a vida e obra desse autor que, segundo ele mesmo, procurou promover no Brasil uma "tenacíssima campanha hispanoamericanista". ${ }^{1}$ O site da Academia Petropolitana de Letras (única referência biográfica do autor encontrada na internet no início da pesquisa) endossa que, pela sua "bagagem literária", sua produção "deveria ser reeditada e adotada pelas cátedras de nossa história hispano-americana". ${ }^{2}$

A princípio, o paradoxo saliente nesses indícios nos levou ao interesse pela sua obra e à reflexão sobre o que a historiografia brasileira seleciona como relevante ou como legítimo para ser lembrado. Sabemos que nos estudos brasileiros sobre a América hispânica há graves lacunas historiográficas que não explicam, por si só, o fato de que muitos intelectuais brasileiros, dedicados a temáticas menos visitadas, sejam desconsiderados, até mesmo pela própria instituição acadêmica, em prol de outros.

Ronaldo Conde Aguiar, ao realizar um trabalho sobre Manoel Bomfim, intitulado $O$ rebelde esquecido, defende que há no meio intelectual brasileiro

\footnotetext{
${ }^{1}$ Essa campanha está relacionada à divulgação, no Brasil, de volumes de crítica, história e folclore sobre a América hispânica, com o objetivo de diminuir o desconhecimento brasileiro com relação a essa “outra” América. In: JULIO, Silvio. Apostolicamente. Rio de Janeiro: Casa d Cervantes, 1926. ${ }^{2}$ Disponível em: http://www.apcl.com.br/noticias/coluna silviojulio.html. Acesso em: 07/09/03.
} 
uma "hierarquia de relevância" que tende a privilegiar autores estrangeiros em detrimento de autores brasileiros. Além disso, há, segundo ele, um consenso de que somente nomes consagrados da história intelectual brasileira são capazes de apontar as causas mais profundas das mazelas sociais e políticas do país. De acordo com essa lógica, os intelectuais pouco conhecidos ou mesmo esquecidos não nos serviriam para pensar a história porque o pensamento social brasileiro é, notavelmente, excludente. ${ }^{3}$

Procurando reavaliar essa concepção de Aguiar, seria interessante pensarmos sobre o esquecimento histórico como um aspecto da memória que opera realizando escolhas. Dessa maneira, a disposição para esquecermos determinados ângulos do passado revela sinais tão significativos sobre o que valorizamos quanto a disposição que temos de lembrar, em grande medida, de determinados acontecimentos e autores.

Diante dessa problemática da lembrança e do esquecimento que envolve o discurso histórico, levantamos algumas questões sobre o trabalho intelectual de Silvio Julio: Por que um intelectual tão erudito e produtivo não é lembrado? O que significava ser, no Brasil, um dos precursores acadêmicos em estudos hispano-americanos? Como explicar a estratificação dentro do campo intelectual, onde alguns autores são reconhecidos e outros esquecidos?

Apesar das dificuldades em lidar com essas indagações, elas são, a nosso ver, extremamente instigantes. Temos a oportunidade de refletir, no Brasil, sobre temas relacionados ao papel da intelectualidade, dos projetos editoriais, do discurso histórico e suas ligações com a política, a memória e, também, nesse caso, com a construção da identidade brasileira em relação à América hispânica.

Nossa intenção, nas linhas que se seguem, é apresentar parte das representações desse precursor acadêmico sobre a América Latina, buscando discutir o que estaria em jogo no seu reconhecimento intelectual: as escolhas tocantes ao objeto - América Latina, a habilidade em estabelecer relações no seu círculo profissional, bem como as linguagens e perspectivas teóricas utilizadas.

\section{Desafios tocantes ao objeto: pensar a América Latina no Brasil}

No período em que Silvio Julio começou a produzir suas obras (1915), o Brasil procurava, segundo Kátia Gerab Baggio, consolidar sua identidade

\footnotetext{
${ }^{3}$ Ver: AGUIAR, Ronaldo Conde. O rebelde esquecido: tempo, vida e obra de Manuel Bomfim. Rio de Janeiro: Anpocs; Topbooks, 2000.
} 
nacional, reforçando, na maioria das vezes, suas diferenças em relação aos países da América hispânica, o que é relativamente compreensível, uma vez que conflitos fronteiriços, principalmente em relação aos países platinos, ajudaram a gerar desconfianças mútuas. No entanto, o Brasil, até hoje, "oscila entre o sentimento de ser, ou não, parte integrante da América Latina". ${ }^{4}$

Diversos historiadores contemporâneos, como José Murilo de Carvalho, Maria Ligia Prado e Maria Helena Capelato, ${ }^{5}$ realizaram estudos para a compreensão dessa questão, ao identificarem e apontarem que a resistência, um tanto quanto preconceituosa, em relação à América hispânica no Brasil, remonta ao período monárquico e, de certa forma, se manteve no início da República; que não há, ainda, uma tradição de estudos sobre a América hispânica no Brasil e o que une os latino-americanos é, muitas vezes, um inimigo comum - os EUA. Além disso, o Mercosul representaria atualmente, na visão de muitos brasileiros, a grande possibilidade de integração e de mútuo conhecimento.

Essa realidade [o Mercosul] obrigou os brasileiros a reverem seus projetos de hegemonia e o significado de sua identidade no continente. A crise dos últimos anos mostrou, como nunca no passado, que a América Latina não é a "Outra América" desprezada, mas a "Nossa América", com a qual nos identificamos. ${ }^{6}$

De acordo com Prado, os discursos de intelectuais brasileiros sobre a América hispânica, ao longo dos séculos XIX e XX, foram, em grande parte e durante muito tempo: "“verdadeiras narrativas míticas' que têm dupla finalidade, a explicativa e a mobilizadora". ${ }^{7}$ Isto é, esses discursos contribuíram para a construção de uma memória negativa a respeito dessa "outra" América, que se firmou no senso comum.

\footnotetext{
${ }^{4}$ BAGGIO, Kátia Gerab. A “outra” América: a América Latina na visão dos intelectuais brasileiros das primeiras décadas republicanas. Tese de doutorado, História Social, FFLCH, Universidade de São Paulo, 1998, p. 209.

${ }^{5}$ Alguns dos artigos em que se encontram as ideias dos referidos autores são: CARVALHO, José Murilo de. Brasil: Outra América? In: Pontos e bordados: escritos de história e política. Belo Horizonte: Ed. UFMG, 1998. PRADO, Maria Ligia Coelho. O Brasil e a distante América do Sul. Revista de História da USP, vol. 145. São Paulo: Ed. Humanitas, 2001, p. 127-149. CAPELATO, Maria Helena. O "gigante brasileiro" na América Latina: ser ou não ser latino-americano. In: MOTA, Carlos Guilherme (org.). Viagem incompleta: A experiência brasileira (1500-2000) - A grande transição. São Paulo: Ed. Senac, 2000.

${ }^{6}$ CAPELATO, Maria Helena. O "gigante brasileiro" na América Latina: ser ou não ser latinoamericano. In: MOTA, Carlos Guilherme (org.). Viagem incompleta: A experiência brasileira (1500-2000) - A grande transição. São Paulo: Ed. Senac, 2000, p. 315.

${ }^{7}$ PRADO, Maria Lígia Coelho. O Brasil e a distante América do Sul. Revista de História da USP, vol. 145. São Paulo: Ed. Humanitas, 2001, p. 132.
} 
Assim, as obras de Silvio Julio foram produzidas em momentos de relativo desinteresse e preconceito do Brasil em relação aos países hispano-americanos. Realizando uma oposição a essa tendência negativa, o autor afirma, nos seus estudos, que a América hispânica merece ser pesquisada pelos brasileiros porque temos uma tradição ibérica em comum, o que proporciona uma identificação mútua, sendo essa tradição considerada, na visão dele, a principal constituinte da nossa "Pátria Maior" - a América Latina. ${ }^{8}$

Essa dedicação voltada a "Pátria Maior" é confirmada, por exemplo, ao observarmos que as referências por ele utilizadas em seus livros são, na grande maioria, de fontes hispano-americanas, e que suas relações com muitas das universidades desses países foram perceptivelmente estreitas. Além do mais, criticava os discursos brasileiros nacionalistas que sustentavam ser o Brasil o melhor país da América Latina.

Ora, qual a razão de que dispõe o Brasil para, na América, tornar-se senhor da exclusividade em coisas intelectuais? Que misterioso privilégio é esse, que o faz, entre as nações ibéricas do nosso continente, dono da melhor e quiçá única cultura? Por que, não havendo até hoje descoberto o intrínseco caráter de sua mentalidade, nem organizado o seu celular critério filosófico-social, deprecia a labuta do espírito mexicano, que é impressionante, a do espírito colombiano, que é firme, a do espírito platino, que é insaciável? ${ }^{9}$

Vale salientar que, em suas obras, Silvio Julio trabalha como uma espécie de intérprete do pensamento político e cultural hispano-americano no Brasil. O seu esforço está voltado, preponderantemente, para apresentar, ao leitor brasileiro, autores hispano-americanos do século XIX e início do XX. Pensadores como Símon Bolívar, Andrés Bello, José Martí, Ricardo Palma, Manuel González Prada, Rubén Darío, José Enrique Rodó, entre outros, foram alvos de sua dedicação. Procurou também divulgar importantes literatos brasileiros como Lima Barreto e Machado de Assis, em suas idas aos centros intelectuais da América hispânica. Orgulhava-se de frequentar diversas academias de história, letras e folclore na América Latina em defesa do mútuo conhecimento entre esses países: "Imprensa, livrarias, agremiações de fraternidade hispano-brasileira - eis a base de ação [divulgadora] a desenvolver". ${ }^{10}$

\footnotetext{
${ }^{8}$ JULIO, Silvio. Cérebro e coração de Bolívar. $3^{\mathrm{a}}$ ed. Salvador: Livraria Progresso, 1957, p. 5.

${ }^{9}$ JULIO, Silvio. Escritores antilhanos. Rio de Janeiro: H. Antunes, 1944, p. 15.

${ }^{10}$ JULIO, Silvio. Apostolicamente. Rio de Janeiro: Casa de Cervantes, 1926, p. 176.
} 
É possível que o já comentado preconceito dominante no Brasil em relação à América hispânica, constatado pela historiografia contemporânea, tenha contribuído para silenciar uma voz acadêmica dissonante que trazia a problemática da latinidade americana, ou melhor, ibero-americana como um contraponto ao discurso nacionalista predominante na primeira metade do século XX.

É fato que todo preconceito é significativo na constituição de uma identidade, pois só temos preconceito em relação àquilo que nos incomoda ou ameaça. ${ }^{11}$ Mario de Andrade reforça essa ideia através da literatura, em seu texto inacabado O banquete, de 1944, ao afirmar que somos mais próximos do que imaginamos da América hispânica, daí a necessidade das diferenças serem tão realçadas.

Nós somos um terreno de luta, não só comercial, mas cultural para as nações de primeira grandeza. E com a guerra, com a derrota da França, a América do Norte aproveitou a ocasião, pra ver si nos dominava culturalmente também. Empregou métodos excelentes, e hábeis quase todos, e não há dúvida que a cultura latina, especialmente a francesa esta periclitando aqui. É um bem? É um mal. Nós não somos "latinos" eu sei. Mas também não somos norte-americanos. Nossa cultura nacional ainda é demasiado frágil pra não sofrer consequências funestíssimas si se ianquizar. É engraçado: há culturas cuja influência é perigosa, e outras não. Por exemplo, eu acho a cultura espanhola muito perigosa pra nós, porque desvirtua os caracteres íntimos da língua nacional. Toda influência cultural enche uma língua de estrangeirismos, não há dúvida. Mas é curioso como um galicismo, um anglicismo, um germanismo não deturpam a sensibilidade psicológica da nossa síntese. Talvez por virem de linguagens distantes demais da nacional. Mas os italianismos e sobretudo os espanholismos, por isso mesmo que muito mais sutis, muito menos "visíveis", têm o dom terrível de deturpar as essências íntimas da nossa linguagem. ${ }^{12}$

O nacionalismo brasileiro percebia a América hispânica como uma ameaça às "especificidades brasileiras", na medida em que as semelhanças existentes entre as línguas, as culturas e as religiões desses países eram inegáveis. Nessa direção, podemos deduzir que o discurso nacionalista contribuiu para obstaculizar o conhecimento mais profundo sobre a América hispânica, no Brasil.

A interpretação de Silvio Julio diante dessa temática foi encoberta, durante um longo período, e, desse modo, procuraremos dar voz a ela não só para repensarmos o preconceito nas relações entre o Brasil e a América hispânica, constatado pela atual historiografia brasileira, como também para pensar o seu

\footnotetext{
${ }^{11}$ Ver:TODOROV,Tzevetan. A conquistadaAmérica: aquestãodooutro. SãoPaulo: MartinsFontes, 2003. ${ }^{12}$ ANDRADE, MARIO. O banquete. São Paulo: Ed. Duas Cidades, 1977, p. 108 (grifos nossos).
} 
lugar no meio intelectual. $\mathrm{O}$ autor acreditava que a excessiva ênfase em uma relação conflituosa e preconceituosa não é de forma alguma profícua, uma vez que não cria uma melhor alternativa de conhecimento e convivência entre os países.

Intelectuais como João Ribeiro, Silvio Romero, Elísio de Carvalho dedicaramse, segundo Silvio Julio, a alguns aspectos culturais latino-americanos, mas "nunca persistiram na pesquisa e meditação do total de feições da problemática novo-mundista". Anteriormente a ele, um dos únicos a se dedicar à defesa de uma visão sobre a América hispânica mais positiva foi Manoel Bomfim, porém Silvio Julio afirmava que coube a Silvio Romero ter dado um "mau fim" a esse primeiro esforço. ${ }^{13}$

Seguramente, Silvio Julio não foi o único a perceber, a problematizar e a valorizar as identidades latino-americanas no largo período em que escreveu. Gilberto Freyre, ${ }^{14}$ por exemplo, foi mais um dos diversos autores que se debruçaram sobre essa temática. No entanto, o que caracteriza Silvio Julio é o fato de ter sido um precursor acadêmico dos estudos hispano-americanos no Brasil, com uma postura militante em prol do mútuo conhecimento entre os países latino-americanos. De acordo com o autor: "A falta de informações costuma os apressados daqui, a rebentar de vaidade infantilmente localista, juntar o desprezo cruel e absurdo da obra dos maiores heróis, estadistas, sábios e literatos da América Espanhola". Mais adiante acrescenta:

Quando provamos a colegas ilustres que nem sempre fomos nós os primeiros defensores e os mais evidentes dos princípios de solidariedade continental, que não criamos as primeiras escolas e universidades do Novo Mundo, que não nos pertencem as suas primeiras obras literárias e tipográficas, eles nos confessam lealmente a surpresa que isto lhes causa, pois pensavam que todas as iniciativas e glórias americanas partiam do Brasil. Ao menos esses são honrados e escutam a lição da verdade. Pior, milhões de vezes pior é a gentalha discursadora dos centros aonde se arranjam empregos oficiais, que tal escória da inteligência humana se nega a curvar-se aos fatos e aos documentos e ainda calunia o homem livre que os expõe, chamando-lhe de mau cidadão, traidor e diabo. ${ }^{15}$

\footnotetext{
${ }^{13}$ JULIO, Silvio. [s.d.]; s/p. Vale destacar que as ideias de Manuel Bomfim sobreaAmérica Latina ficaram durante muito tempo esquecidas pela historiografia brasileira. Somente a partir dos anos de 1980, a obra foi devidamente recuperada e revalorizada. Livros como Estilo tropical de Roberto Ventura e Manuel Bomfim: o rebelde esquecido de Ronaldo Conde Aguiar são algumas obras expressivas nessa direção. ${ }^{14}$ Veja: FREYRE, Gilberto. Americanidade e latinidade da América Latina e outros textos afins. São Paulo: Imprensa Oficial, 2003.

${ }^{15}$ JULIO, Silvio. Escritores antilhanos. Rio de Janeiro: H. Antunes, 1944, p. 6.
} 
O Instituto Histórico e Geográfico Brasileiro, segundo Silvio Julio, era um exemplo "suspeitíssimo" de conhecimento histórico que congregava parte dessa "gentalha discursadora dos centros aonde se arranjam empregos oficiais", pois a insistência ufanista de seus membros em pensar a história a partir da nação tinha como consequência a exagerada glorificação do passado nacional, o reconhecimento intelectual fácil e cômodo, e o grave comprometimento na compreensão de outros países e culturas, uma vez que a exaltação do Brasil gerava, muitas vezes, um sentimento de superioridade.

No período em que o autor começou a produzir seus trabalhos, a postura crítica sobre a nação não era tão recorrente. É interessante constatar que, nos últimos tempos, a crítica sobre o nacionalismo é aceita frequentemente no meio intelectual, uma vez que as grandes ideologias desmoronaram e a história ampliou os seus objetos. Não obstante, como afirma Prado, pensar a história a partir da nação é, ainda, uma forma preponderante para a compreensão desse saber: "A força persuasiva do nacionalismo continua presente e fortemente estabelecida tanto no cenário da política como também no mundo universitário, onde a centralidade das disciplinas referidas à história nacional é prova cabal dessa visão hegemônica."”16

\section{Uma militância passional}

É importante acentuar que a sociabilidade intelectual e política de Silvio Julio sempre estiveram ameaçadas pelo fato de o autor possuir um temperamento forte que o fazia criar grandes inimizades e viver uma vida de instabilidades. Vejam-se, por exemplo, as observações da historiadora Eulália Lobo que, sob a orientação de Silvio Julio, doutorou-se e lecionou História da América na Universidade do Brasil (atual UFRJ): “Todo mundo ficava espantado como durante tantos anos ele não brigou comigo. Acabou brigando, mas antes trabalhamos juntos muito tempo. Ele brigava com todo mundo, era uma pessoa irascível, um temperamento dificílimo". ${ }^{17}$ Para o autor, esse temperamento agressivo era uma forma de luta por uma área de estudos muito pouco valorizada pelos intelectuais brasileiros na primeira metade do século XX - a América Latina.

\footnotetext{
${ }^{16}$ PRADO, Maria Lígia Coelho. Repensando a história comparada na América Latina. Revista de História da USP, vol 153 ( $2^{\circ}$ semestre). São Paulo: Ed. Humanitas, 2005, p. 11-33.

${ }^{17}$ LOBO, Eulália Maria Lahmeyer. Entrevista. Estudos Históricos, vol. 5, n. 9. Rio de Janeiro, 1992, p. 84-96.
} 
Quem escreve no Brasil, sobre literatura hispano-americana, sabe que tem de enfrentar muitas dificuldades. Por isso, convém que as vença, prevenindo-se contra os prejuízos e calúnias. Antes de qualquer ato, o que cumpre ao investigador é conhecer as barreiras, perigos e ciladas, para combater todos esses absurdos e conseguir implantar a verdade. Sem a determinação clara de cada antipatia, sem a avaliação completa de cada despautério, inútil será o esforço mais nobre. Assim, o historiador e crítico da cultura dos povos novo-mundistas que falam o castelhano se vê forçado sempre à polêmica. ${ }^{18}$

Silvio Julio, em diversos momentos de suas obras, como em seu livro Apostolicamente, de 1926, adverte "quanta risadinha idiota, quanto ar de displicência cretina tivemos que suportar! Evidentemente, envolvida pela maioria galicista, uma seleta minoria prestou-nos atenção". ${ }^{19}$ A minoria à qual Silvio Julio se refere compõe-se de intelectuais como Barbosa Lima, Pinto da Rocha, Zeferino Brasil, Rocha Pombo, Basílio de Magalhães, Carlos Maúl, Ronald de Carvalho, Tasso da Silveira.

Ao longo de sua trajetória, o autor também teve contatos com outras personalidades relevantes do meio intelectual latino-americano, como Alceu Amoroso Lima, Cecília Meireles, Fernando Ortiz, Gabriela Mistral, Luis Alberto Sánchez, Luis da Câmara Cascudo, Pedro Calmon entre outros, o que revela uma sociabilidade bastante significativa. Entretanto, as suas posturas em relação às questões do seu tempo foram, em grande medida, movidas por esse temperamento enérgico, e contundente, que acreditamos ter comprometido a sua inserção em diversos debates e possivelmente o reconhecimento pelo seu trabalho como intelectual ibero-americanista, no Brasil. O próprio autor reconhecia, em livro publicado em 1983, os problemas causados pelo seu forte temperamento:

Não adivinho se me assemelho à nuvem carregada de eletricidade, ou ao para-raios que lhe envia a carga à terra. Sei que me prejudicou em toda a existência captar desgostos e acusá-los, ao mesmo passo que, após o esvaziamento dos dissabores, esquecer tudo. Violento fui por índole, impetuoso fui de natureza. Entretanto, rancoroso e vingativo, nunca. ${ }^{20}$

Para Silvio Julio, escrever e lecionar significava induzir uma mudança na forma como os brasileiros compreendiam a América Latina. Constatamos que, para ele, isso não era apenas um trabalho, mas uma missão a ser cumprida.

\footnotetext{
${ }^{18}$ JULIO, Silvio. Escritores antilhanos. Rio de Janeiro: H. Antunes, 1944, p. 5.

${ }^{19}$ JULIO, Silvio. Apostolicamente. Rio de Janeiro: Casa de Cervantes, 1926, p. 11.

${ }^{20}$ JULIO, Silvio. Sobre história, arqueologia e linguística. Rio de Janeiro: Continente Editorial, 1983, p. 290.
} 
Certos adamados e pelintras nos censuram o tom combativo de nossos livros, artigos, conferências e discursos. Acham eles que o melhor de uma propaganda está em não discutir. Aconselham que exponhamos apenas e nos consagremos à tradução. Querem, portanto, que reduzamos o trabalho intelectual à bio-bibliografia e ao pacifismo suspeitíssimo das versões.

Esses macios e gelatinosos sujeitos ignoram a verdadeira situação nacional do problema. Ajuntam-no a seu modo. Incapazes de reações, covardes por natureza, despersonalizados, pretendem acorrentar o pensamento às regrinhas acadêmicas ou a ridículas hipocrisias da sociabilidade dos miméticos. Não suportam moluscos que voem águias. ${ }^{21}$

O "tom combativo", ríspido, ofensivo e preconceituoso do seu discurso é elemento de uma luta para se fazer ouvir, por meio de uma propaganda polêmica. De acordo com Roberto Ventura, a linguagem da luta é parte do discurso da polêmica. Acreditava-se, principalmente no final do século XIX e início do XX, que esse estilo contribuiria para o processo de seleção e depuração das obras de escritores, lançadas ao público na luta pela existência: "A ciência evolucionista, com ênfase na luta entre espécies, justificava a violência de tais debates como necessária à propagação das novas ideias e ao aperfeiçoamento cultural e social". ${ }^{2}$

No entanto, no Brasil, esse "estilo tropical", ao longo do século XX, foi perdendo espaço com a construção e a especialização de um conhecimento científico, o que fazia dessa linguagem agressiva no universo acadêmico, muitas vezes, um discurso autoritário e improdutivo. Desse modo, é interessante pensar como as origens, no Brasil, da especialização acadêmica sobre história da América não necessariamente determinou a forma como o conhecimento foi posteriormente veiculado e legitimado.

\section{Perspectiva metodológica e teórica : Bolívar, Rodó e José Martí}

Em entrevista realizada, no ano de 1992, na Revista de Estudos Históricos da UFRJ, Eulália Lobo expressa uma severa crítica a Silvio Julio pela sua visão militante da História.

Meu orientador foi o Silvio Julio, mesmo porque não havia outra escolha. E foi uma loucura total. Qualquer assunto de que eu falasse, ele entrava pela preocupação fundamental dele, que era falar mal dos portugueses. Não era uma coisa elaborada, era passional. Ele

\footnotetext{
${ }^{21}$ JULIO, Silvio. Escritores antilhanos. Rio de Janeiro: H. Antunes, 1944, p. 6.

${ }^{22}$ VENTURA, Roberto. Estilo tropical: História cultural e polêmicas literárias no Brasil 18701914. São Paulo: Companhia das Letras, 1991, p. 80.
} 
defendia o mundo hispânico, Bolívar era o herói máximo! Era aquela história de heróis, de paradigmas, história exemplar. ${ }^{23}$

Além do mais, a historiadora aponta a ausência de metodologia, formação teórica e historiográfica nos trabalhos acadêmicos do autor sobre história da América: "não tinha metodologia alguma. Também não tinha formação, como a maioria dos professores. E este era o grande problema do curso de História: havia uma atitude antimetodológica". ${ }^{24}$ Eulália Lobo tem razão quanto à falta de um rigor metodológico, porém é preciso salientar que, como ela mesma lembrou, a especialização historiográfica, no Brasil, estava nos seus inícios. Na defesa de uma lógica própria para a compreensão da história da América, Silvio Julio foi o precursor brasileiro, nos anos de 1940, na especialização acadêmica nessa área, em um período em que a Universidade do Brasil possuía $60 \%{ }^{25}$ das disciplinas de História ministradas em francês.

Para Eulália Lobo, ainda sim, Silvio Julio “possuía uma erudição enorme, uma biblioteca fantástica", o que o muniu na luta para tentar reconstruir histórias pouco estimadas pela intelectualidade brasileira, pois os seus textos demonstram um vasto conhecimento sobre diversos aspectos culturais da América Latina. ${ }^{26}$ Quanto à sua linguagem, não se importava com embaraços ou constrangimentos, uma vez que empenhava sua argumentação em contestar determinadas visões da historiografia brasileira. Nesse sentido, podemos observar, uma vez mais, a sua reação parcial e emocional sobre as diferenças entre o Brasil e a América hispânica:

Chegou-se a sustentar no Brasil, estaparfúdia, a premissa que aparentemente servia de ponto de partida ao ufanismo hiperbólico dos lusófilos e monarquistas: Quem fala não se entende com quién habla.

\footnotetext{
${ }^{23}$ LOBO, Eulália Maria Lahmeyer. Entrevista. Estudos Históricos, vol. 5, n. 9. Rio de Janeiro, 1992, p. 87. ${ }^{24}$ LOBO, Eulália Maria Lahmeyer. Entrevista. Estudos Históricos, vol. 5, n. 9. Rio de Janeiro, 1992, p. 85.

${ }^{25}$ De acordo com a historiadora Maria de Lourdes de Fávero: "Nessa época, a FNFi tinha uma influência francesa muito grande, pelo menos no curso de História e Geografia. Vários professores eram franceses: Antoine Bon, de História Antiga, o professor Tapié, de História Moderna, o professor Ruellan, de Geografia do Brasil. Realmente, a tal ponto era essa influência que alguns exames eram feitos em francês. Isso ocorreu por volta de 1939, pois me formei na primeira turma, em 1942. Época de guerra! Alguns franceses que vieram em caráter transitório não voltaram e ficaram aqui durante toda a Segunda Guerra Mundial. (...) Pelo menos 60\% das matérias eram dadas em francês." In: FÁVERO, Maria de Lourdes de. (coord.). 5 depoimentos. Rio de Janeiro: UFRJ, 1991, p. 198. ${ }^{26}$ LOBO, Eulália Maria Lahmeyer. Entrevista. Estudos Históricos, vol. 5, n. 9. Rio de Janeiro, 1992, p. 86.
} 
Diz-se que tão perniciosa e bestial toleima, que a prática de uma diplomacia republicana vai, agora, começando a atenuar, foi como cogumelo peçonhento no cérebro de certo partidário do decaído regime bragantino. ${ }^{27}$

Apesar das críticas à herança portuguesa e ao IHGB, a história produzida por Silvio Julio era, em grande parte, uma história exemplar e heróica de alguns dos principais pensadores e líderes políticos hispano-americanos como Simón Bolívar. Sua obra é caracterizada pelo próprio autor como ibero-americanismo bolivariano, o que implicava na valorização das tradições ibéricas dando ênfase ao Bolívar como um herói precursor da ideia e da luta pela América unida.

Simón Bolívar, El Libertador, que foi este apóstolo supremo e imparizável campeão da solidariedade dos povos do Novo-Mundo, ponderando todas as razões essenciais, não só estabeleceu as leis que solidificam a doutrina, como determinou, pragmática e concretamente, os meios para executá-la. Ele não estacionou em fórmulas indecisas ou sonhos românticos de fraternidade sentimental, mas recomendou a assembleia permanente dos plenipotenciários, das repúblicas livres, que se constituíssem na América, cuja missão seria manter a paz, esclarecer dúvidas, incentivar aproximações, nunca ofender e violar o direito. Eis a síntese dos seus princípios: "Uma única deve ser a pátria dos americanos, já que em tudo tivemos uma perfeita unidade". 28

É importante mencionar que Bolívar não incluía nos seus planos o Brasil, ou seja, a sua luta esteve relacionada à construção de uma liga das nações hispanoamericanas. Porém, a capa de uma das edições do livro de Silvio Julio sobre Bolívar-Cérebro e coração de Bolívar -, de 1981 (1 $1^{\mathrm{a}}$ edição, 1931), trazia à frente um retrato de Bolívar em cores iguais às da bandeira do Brasil - verde, amarelo e azul. O que nos leva a crer que o autor queria forjar um Bolívar para o Brasil. A figura de Bolívar deveria ser, segundo o autor, considerada heróica pelos brasileiros não só por representar a luta pela integração das nações latino-americanas, mas, também, por ser uma referência exemplar à defesa dos ideais republicanos. Silvio Julio destacou, em seus textos, homens como frei Caneca e Abreu e Lima que lutaram pela república brasileira no período monárquico e souberam valorizar Bolívar: "Bolívar es el único americano completo, es el único cuya acción genial y humana se proyecta en la historia de la América Portuguesa" 29.

\footnotetext{
${ }^{27}$ JULIO, Silvio. Sobre história, arqueologia e linguística. Rio de Janeiro: Continente Editorial, 1983, p. 277.

${ }^{28}$ JULIO, Silvio. Escritores antilhanos. Rio de Janeiro: H. Antunes, 1944, p. 34.

${ }^{29}$ JULIO, Silvio. Venezuela. Rio de Janeiro: Universidade do Brasil, 1940, p. 143.
} 
O fato de Silvio Julio considerar Bolívar como o herói mais importante de toda a América Latina revelava uma outra contradição em sua argumentação. A contradição está no fato de Bolívar ter rejeitado toda a herança ibérica no processo das independências hispano-americanas e os ibero-americanistas terem resgatado a sua trajetória histórica sem revelarem as complexas posições republicanas e autoritárias de Bolívar. Além disso, essa visão era um tanto quanto difícil de ser aceita pelo meio intelectual brasileiro, uma vez que o que se buscava, em boa medida, era vangloriar figuras brasileiras.

De acordo com Prado, o Bolívar "brasileiro" é, ainda hoje, "uma figura distante e pouco conhecida, pois que o Brasil não precisa de heróis latinoamericanos (na verdade, gostaria de criar heróis brasileiros para a América Latina)". ${ }^{30}$ No entanto, para ele, a resistência ao reconhecimento, no Brasil, da importância histórica de Bolívar ocorria, também, porque diversos intelectuais brasileiros olhavam para a história americana com um olhar europeu: "Para apreciá-lo [Bolívar] devida e honestamente, fujamos de preconceitos, compromissos e tradições filosóficas da orgulhosa Europa, que submete a realidade americana a seus caprichos e dogmas". ${ }^{31}$

A compreensão de Silvio Julio sobre a América Latina foi significativamente influenciada, além de Bolívar, pelo pensador uruguaio José Enrique Rodó (18711917), principalmente por conta de sua obra Ariel. É sabido que o livro, publicado em 1900, se tornou um clássico do pensamento latino-americano, ao questionar o acelerado processo de modernização capitalista, criticar duramente o american way of life e valorizar as heranças greco-latinas e católicas da América ibérica.

Em 1954, Silvio Julio publica - José Enrique Rodó e o cinquentenário do seu livro Ariel com o intuito de apresentar o pensador e suas ideias aos brasileiros. De acordo com Antonio Mitre, o ensaio de Rodó - Ariel -, depois de inicialmente ser muito prestigiado, acabou paulatinamente sendo esquecido quando o mito de uma América Latina espiritual e unida entrou em crise. ${ }^{32}$ Entretanto, Silvio Julio afirmava que, no Brasil, a obra de Rodó não chegou a sequer ser reconhecida.

Ariel, ao sair do prelo e ao deslumbrar americanos e espanhóis, não foi sabido no Brasil, de maneira nenhuma. Glorioso e triunfante, traduzido e comentado, ficou oculto de nosso

\footnotetext{
${ }^{30}$ PRADO, Maria Ligia Coelho. Bolívar, bolívares. Folha de S.Paulo, 27/07/1983. São Paulo.

${ }^{31}$ JULIO, Silvio. Ensaios sobre a história dos povos americanos. Rio de Janeiro: Nepec, 1961, p. 134.

${ }^{32}$ MITRE, Antonio. O dilema do centauro: Ensaios de teoria da história e pensamento latinoamericano. Belo Horizonte: Ed. UFMG, 2003.
} 
país, que não participou de tão justa consagração, visto que vivíamos de costas para o Novo-Mundo e genunflexos a qualquer excrescência francesa.

Lembremo-nos perfeitamente de nosso esforço titânico, indescritível, para conseguirmos, de 1912 a 1930, que os intelectuais brasileiros ao menos lessem as páginas americanistas de Ariel. $^{33}$

O fato de Ariel ter tido, no Brasil, uma repercussão limitada estava fundamentalmente relacionado, para ele, com a herança da Monarquia portuguesa que insulou o país, na América, com atos "imperialistas": "Pagávamos o tributo à educação lusa que nos viera nos dias do coloniato, à política da monarquia incivil de Pedro I e do gélido Pedro II". ${ }^{34}$

Vale salientar que, desde o início do século XX, os hispano-americanos possuíam uma ligação cultural muito mais forte e expressiva com o ex-colonizador do que os brasileiros. Alguns fatores, como a interferência norte-americana em vários países da América Central e do Caribe, desde o final do século XIX, contribui para explicar essas diferenças, pois gerou, entre os hispano-americanos, uma resistência aos EUA e uma revalorização, por diversos intelectuais, das tradições ibéricas. Como afirma Maria Helena Capelato, a revalorização da cultura ibérica na América hispânica ocorreu, no final do século XIX, com o processo de independência cubana que propiciou a aproximação de escritores espanhóis e hispano-americanos.

Em sua grande maioria, os intelectuais do final do XIX questionaram os valores de uma cultura expansiva - a anglo-saxã - cuja impetuosa modernidade se impôs sobre a tradição humanista da cultura latina que esteve na base da cultura ibérica. A discussão que se travou em nome da cultura saxã versus cultura latina serviu para unir espanhóis e hispano-americanos. ${ }^{35}$

O ibero-americanismo defendido por Silvio Julio foi construído, nessa direção, em grande medida, por pensadores hispano-americanos dessa época que afirmavam as identidades ibero-americanas ou latino-americanas em contraponto aos Estados Unidos. A contraposição da "raça latino-americana" à "raça angloamericana" propiciava um debate acalorado entre diversos intelectuais que, ou supervalorizavam os Estados Unidos, como era o caso de muitos liberais, ou criticavam os mesmos, como faziam muitos intelectuais ibero-americanistas.

\footnotetext{
${ }_{33}^{3}$ JULIO, Silvio. José Enrique Rodó eo cinquentenário do seu livro Ariel. Rio de Janeiro: MEC, 1954,p. 6.

${ }^{34}$ JULIO, Silvio. JoséEnriqueRodó eo cinquentenário do seulivro Ariel. Riode Janeiro: MEC, 1954,p. 15.

${ }^{35}$ CAPELATO, Maria Helena. Adata símbolo de 1898: o impacto da independência de Cuba na Espanha e Hispanoamérica. Revista de História da USP, vol. 22, n. 2. São Paulo: Editora Unesp, 2003, p. 38.
} 
A ênfase dada por Silvio Julio à divulgação da cultura hispano-americana no Brasil justifica-se pelo fato de que, para ele, o envolvimento dos brasileiros com a defesa da integração latino-americana foi extremamente precário. O grande pivô desse fato foi, principalmente, como mencionamos anteriormente, para o autor, a herança portuguesa que insulou os brasileiros na América. Em entrevista, no ano de 1938, ao jornal colombiano La Razón, o autor afirmou: "El Brasil debe muy poco a Portugal. Nuestro progreso es reciente". ${ }^{36}$ Em um jornal venezuelano, El Universal, ele afirmou, na mesma época: "La tradición cultural del pueblo brasileño es menos antigua que la de los países hispano-americanos. (...) Los portugueses nunca se preocuparon con la instrucción pública de su opulenta colónia". ${ }^{37}$

De acordo com o autor, a colonização portuguesa foi para o Brasil sinônimo de atraso não só econômico como cultural, pois nunca os colonizadores se preocuparam com "a instrução pública". Já no caso da colonização espanhola foram fundadas 23 universidades na América, apesar dessas serem regidas por um ensino religioso.

Não importa que na Universidade de São Marcos, em Lima, a teologia fosse o principal e ficasse acima do direito, da filosofia, da matemática, da medicina. A Europa inteira, durante as XVI.a e XVII.a centúrias, fazia o mesmo. Como iriam os hispano-americanos passar à frente de seus modelos e adivinhar o futuro? Não é ilógico exigir dos povos do Novo Mundo o ensino da física, da química, da mecânica, num tempo em que alemães, franceses, italianos, ingleses, espanhóis, belgas, holandeses, todos, todos davam mais importância à metafísica do que a Ciência. (...) Com erros ou sem erros, a verdade é que tais debates e esforços geravam progresso e inteligência, conhecimentos e emoções, espiritualidade e idealismo, não trevas e indiferença. ${ }^{38}$

Diante dessa visão positiva da experiência colonial da América espanhola, cabe assinalar que a história e a cultura do Brasil que Silvio Julio valorizava e divulgava para os intelectuais hispano-americanos era a história do Brasil republicano. No jornal colombiano, já mencionado, La Razón, o autor chamou a atenção para as características "essenciais" que compunham "a nação brasileira": "La violencia no estuvo jamás en el caráter del brasileño. Para que nuestro gobierno se mantega es indispensable que sea cristiano, bueno, hábil, democrático, verdaderamente republicano" 39 .

\footnotetext{
${ }^{36}$ JULIO, Silvio. Toda América. Rio de Janeiro: Gráfica Alba, 1939, p. 247.

${ }^{37}$ JULIO, Silvio. Venezuela. Rio de Janeiro: Universidade do Brasil, 1940, p. 141.

${ }^{38}$ JULIO, Silvio. Sobrehistória, arqueologiaelinguística. Riode Janeiro:ContinenteEditorial, 1983, p. 25.

${ }^{39}$ JULIO, Silvio. Toda América. Rio de Janeiro: Gráfica Alba, 1939, p. 250.
} 
Muitas reflexões de Silvio Julio sobre a América Latina possuem substantivas semelhanças com o americanismo de José Martí (1853-1895), explicitadas em seus livros, como Escritores antilhanos de 1944. Optamos por esta passagem de Nossa América a fim de demonstrar algumas aproximações.

Conhecer o país, e governá-lo conforme o conhecimento, é o único modo de livrá-lo de tiranias. A universidade europeia deve dar lugar à universidade americana. A história da América, dos incas pra cá, deve ser ensinada minuciosamente, mesmo que não se ensine a dos arcontes da Grécia. A nossa Grécia é preferível a Grécia que não é nossa. Nos é mais necessária. Os políticos nacionais substituirão os políticos exóticos. Enxerte-se em nossas repúblicas o mundo; mas o tronco terá que ser o de nossas repúblicas. E cale-se o pedante vencido; pois não há pátria na qual o homem possa ter mais orgulho do que em nossas doloridas repúblicas americanas (Martí, 1991: 197).

José Martí acreditava que o conhecimento sobre o passado evitaria a apropriação e reprodução de valores contrários à cultura latino-americana. $\mathrm{O}$ escritor não desvalorizava o valor da Europa, mas questionava a subserviência do intelectual latino-americano. "Os jovens saem pelo mundo adivinhando as coisas com os óculos ianques ou franceses, e pretendem dirigir um povo que não conhecem". ${ }^{40}$

A resistência ao imperialismo norte-americano em Cuba gerou, tanto em José Martí quanto em outros intelectuais cubanos, um sentimento latino-americanista mais veemente do que em muitos outros países. As ideias bolivarianas chegaram a fazer parte de sua filosofia internacionalista, em favor de uma "grande confederação latino-americanista". ${ }^{41}$ Em entrevista ao jornal colombiano El Espectador, do dia 23 de julho de 1938, Silvio Julio endossou essa perspectiva americanista de José Martí sobre a necessidade de autonomia intelectual e revelou-se um profundo "creyente en el futuro de América".

La cosa que más nos molesta en América no es, naturalmente, el culto y el respecto por los genios europeos, es la humilde y reprochable sumisión intelectual de nuestros hombres a ciertos maestrillos de exportación que valen muy poco, pero que se cree, solo pór ser de Europa, que tienen inmenso valor y son superiores a nosotros. (...) América, agrega, sufre el mal de los monos: la imitación servil, el "macaquismo", la servidumbre intelectual. Son pocos los que combaten esta enfermedad. La mayoria se contenta con copiar modalidades morbosas de la caduca Europa. Cierto es que somos la continuación

\footnotetext{
${ }^{40}$ MARTÍ, José. Nossa América: Antologia. São Paulo: Editora Hucitec, 1991, p. 195.

${ }^{41}$ GOTT, Richard. Cuba: uma nova história. Rio de Janeiro: Jorge Zahar, 2006, p. 105.
} 
de Europa, mas no la misma Europa. El hijo depende hasta cierto punto del padre, pero no es el padre sin nada más. Nuestro orgulho deve de estar, sobre todo, en ser una fuerza nueva, derivada de la cultura europea, no en ser agentes vulgares y esclavizados de los gustos y pretensiones de muchos europeos a veces mediocres ${ }^{.42}$

A luta pela autonomia intelectual e política da América Latina, sem desconsiderar o valor positivo da influência europeia na mesma, foi uma bandeira levantada por diversos intelectuais latino-americanos. Em relação à influência norte-americana, a reação de resistência foi fundamental para muitos intelectuais que viam na "cultura norte-americana" o avesso da "cultura latino-americana". Para Silvio Julio, assim como para Rodó: "O pan-americanismo é obra de diplomatas, de brindes e de banquetes. O ibero-americanismo, ao contrário, promana do coração das multidões, do sangue das populações ibéricas da América, da própria estrutura mental, etnográfica e sociológica do Novo-Mundo"43.

Nesse tópico, foi possível notar o diálogo de Silvio Julio com algumas das principais matrizes do debate intelectual latino-americano. $\mathrm{O}$ autor, ao compreender Bolívar como herói, Rodó como um intelectual portador de uma doutrina a ser seguida e José Martí como uma figura exemplar, demonstrou uma profunda admiração por suas vidas, além de evidenciar muito dos próprios silêncios temáticos dos mesmos.

Como exemplo, Silvio Julio silenciou, em suas obras, sobre a questão indígena. Uma hipótese para isso seria o fato de que o indigenismo conseguiu questionar, em boa medida, as concepções hispanistas e gerar uma autoconsciência nacional identificada com o mundo indígena ou com as suas derivações mestiças. ${ }^{44}$ Outro ponto significativo silenciado pelo autor é o fato de que muitos hispano-americanistas, ao se referirem ao latino-americanismo, não incluíam o Brasil. Mônica Quijada, no seu texto Sobre el origen y difusión del nombre "América Latina", afirma que:

De hecho, la primera propuesta de unidad latinoamericana que incorporó una discusión sistemática sobre la incursión del Brasil fue la expuesta por Manuel Ugarte a comienzos del siglo XX, a partir de la idea ya mencionada de la 'nación latinoamericana. ${ }^{45}$

\footnotetext{
${ }_{42}$ JULiO, Silvio. Toda América. Rio de Janeiro: Gráfica Alba, 1939, p. 206. ${ }^{43}$ JULIO, Silvio. Cérebro e coração de Bolívar. $3^{\mathrm{a}}$ ed. Salvador: Livraria Progresso, 1957, p. 307.

${ }^{44}$ Ver: CORNEJO POLAR, Antonio. O condor voa: Literatura e cultura latino-americanas. Tradução de Ilka Valle de Carvalho. Belo Horizonte: Editora UFMG, 2000.

${ }^{45}$ QUIJADA, Mónica. Sobre el origen y difusión del nombre "América Latina" (o una variación heterodoxa en torno al tema de la construcción social de la verdad). Revista de Indias, vol. LVIII, n. 214. Espanha: CSIC, 1998, p. 611.
} 
Para o autor, foi a hipervalorização do capitalismo e do marxismo, ao longo do século XX, em contraponto ao espiritualismo que comprometeu fundamentalmente a compreensão do idealismo de importantes figuras da história latino-americana.

Vivimos en un tiempo opaco, comercial, estúpido, cuyo signo es la cifra de banco, Marx sobre el sublime Crucificado: es nuestra época de materialismo e covardia. Como vamos a sentir la heroicidad divina del martírio? Como vamos a entender el sacrifício supremo del enorme Bolívar, del talentoso y liberal Santander, del sereno y abnegado Sucre, del extraordinario Ricaurte, del terrible y telúrico Paez, del arrogante Córdoba? Vamos hablar de coraje a un vendedor de cebollas! $!^{46}$

Assim, algumas das mais expressivas interpretações que procuraram definir o "espaço cultural latino-americano" como ibérico e católico foram divulgadas e defendidas radicalmente por Silvio Julio, em contraponto a outras tendências mais debatidas não só no Brasil, mas também nos países hispano-americanos, nos anos de 1930, 40, 50 e 60, como o comunismo e o desenvolvimentismo, que pensavam a América Latina sob um outro prisma.

\section{Considerações finais}

A trajetória dissonante de um precursor acadêmico dos estudos hispanoamericanos no Brasil possibilita-nos observar que o reconhecimento intelectual está relacionado às escolhas dos pesquisadores, à linguagem e perspectiva teórica adotada e a uma sociabilidade respeitável. A busca incessante por chamar a atenção ao seu próprio trabalho, como defensor do mútuo conhecimento entre os países latino-americanos, deu ao autor um tom militante que - juntamente com seu temperamento, além de certas características, já apontadas, da sua produção intelectual - contribuiu para o seu esquecimento, inclusive entre aqueles que se dedicam ao mesmo universo temático, a América Latina.

Sabemos que as dificuldades relacionadas à integração entre os países latino-americanos sempre foram, ao longo da história, uma constância. Diversos motivos - econômicos, políticos, sociais e históricos - resultaram em atitudes mútuas de indiferença e preconceito. De acordo com García Canclini, "nos imaginarmos como latino-americanos significa interpretar la persistencia y los cambios de una historia conjunta que se niega". ${ }^{47}$

\footnotetext{
${ }^{46}$ JULIO, Silvio. Ensaios sobre a história dos povos americanos. Rio de Janeiro: Nepec, 1961, p. 207.

${ }^{47}$ GARCÍA CANCLINI. Latinoamericanos buscando lugar en este siglo. Buenos Aires: Paídos, 2002, p. 34.
} 
Ainda sim, a defesa da integração dessa "historia conjunta que se niega" é uma persistência no discurso de diversos intelectuais latino-americanos, como Silvio Julio. Se, em outros momentos, a necessidade e a inviabilidade da integração latino-americana foram justificadas, por exemplo, paradoxalmente pelo imperialismo norte-americano, nos últimos tempos, a luta pela integração desses países ocorre justificada, em grande medida, pelo desconcertante processo de globalização. Dessa forma, as questões pensadas por Silvio Julio, apesar de sua personalidade contraditória, com traços liberais e autoritários, são carregadas de atualidade. É certo que a busca pela "essência" ou pela "identidade" já perdeu espaço, porém, a tarefa política, econômica e intelectual de integração entre esses países esta, ainda, em voga.

\section{Referências bibliográficas}

\section{Fontes}

JULIO, Silvio. Apostolicamente. Rio de Janeiro: Casa de Cervantes, 1926.

JULIO, Silvio. Toda América. Rio de Janeiro: Gráfica Alba, 1939.

JULIO, Silvio. Venezuela. Rio de Janeiro: Universidade do Brasil, 1940.

JULIO, Silvio. Escritores antilhanos. Rio de Janeiro: H. Antunes, 1944.

JULIO, Silvio. José Enrique Rodó e o cinquentenário do seu livro Ariel. Rio de Janeiro: MEC, 1954.

JULIO, Silvio. Cérebro e coração de Bolívar. $3^{\mathrm{a}}$ ed. Salvador: Livraria Progresso, 1957.

JULIO, Silvio. Ensaios sobre a história dos povos americanos. Rio de Janeiro: Nepec, 1961.

JULIO, Silvio. Sobre história, arqueologia e linguística. Rio de Janeiro: Continente Editorial, 1983.

JULIO, Silvio. Manuscritos. Arquivo Pessoal de Francisco Vasconcelos. Juiz de Fora, 2005.

\section{Bibliografia}

AGUIAR, Ronaldo Conde. O rebelde esquecido: tempo, vida e obra de Manuel Bomfim. Rio de Janeiro: Anpocs; Topbooks, 2000.

ANDRADE, Mario de. O banquete. São Paulo: Ed. Duas Cidades, 1977.

BAGGIO, Kátia Gerab. A "outra" América: a América Latina na visão dos intelectuais brasileiros das primeiras décadas republicanas. Tese de doutorado, História Social, FFLCH, Universidade de São Paulo, 1998.

BOLÍVAR, Simón. Escritos políticos. Tradução de Jacques Mario Brand e Josely Vianna Baptista. Campinas: Editora da Unicamp, 1992. 
CAPELATO, Maria Helena. O "gigante brasileiro" na América Latina: Ser ou não ser latino-americano. In: MOTA, Carlos Guilherme (org.). Viagem incompleta: A experiência brasileira (1500-2000) A grande transação. São Paulo: Ed. Senac, 2000.

CAPELATO, Maria Helena. A data símbolo de 1898: o impacto da independência de Cuba na Espanha e Hispanoamérica. Revista de História da USP, vol. 22, n. 2. São Paulo: Editora Unesp, 2003.

CARRERA DAMAS, Germán. El culto a Bolivvar. Caracas: Universidad Central de Venezuela, 1969.

CARVALHO, Eugênio Rezende de. Nossa América: a utopia de um novo mundo. São Paulo: Ed. Anita Garibaldi, 2001.

CARVALHO, José Murilo de. Brasil: Outra América? In: Pontos e bordados: escritos de história e política. Belo Horizonte: Ed. UFMG, 1998.

CORNEJO POLAR, Antonio. O condor voa: Literatura e cultura latino-americanas. Tradução de Ilka Valle de Carvalho. Belo Horizonte: Editora UFMG, 2000.

FÁVERO, Maria de Lourdes de (coord.). 5 depoimentos. Rio de Janeiro: UFRJ, 1991.

GARCÍA CANCLINI, Nestór. Latinoamericanos buscando lugar en este siglo. Buenos Aires: Paídos, 2002.

GOTT, Richard. Cuba: uma nova história. Rio de Janeiro: Jorge Zahar, 2006.

JOSEF, Bella. História da literatura hispano-americana. Rio de Janeiro: Francisco Alves, 1989.

LOBO, Eulália Maria Lahmeyer. Entrevista. Estudos Históricos, vol. 5, n. 9. Rio de Janeiro, 1992, p. 84-96.

MARTÍ, José. Nossa América: Antologia. São Paulo: Editora Hucitec, 1991.

MITRE, Antonio. O dilema do centauro: Ensaios de teoria da história e pensamento latino-americano. Belo Horizonte: Ed. UFMG, 2003.

OLIVEIRA, Lúcia Lippi de. Americanos: representações da identidade nacional no Brasil e nos EUA. Belo Horizonte: Ed. UFMG, 2000.

PRADO, Maria Ligia Coelho. Bolívar, bolívares. Folha de S.Paulo, 27/07/1983. São Paulo.

PRADO, Maria Lígia Coelho. A formação das nações latino-americanas. São Paulo: Atual, 1998.

PRADO, Maria Lígia Coelho. O Brasil e a distante América do Sul. Revista de História - FFLCH/USP, vol. 145. São Paulo: Ed. Humanitas, 2001, p. 127-149.

PRADO, Maria Lígia Coelho. Repensando a história comparada na América Latina. Revista de História - FFLCH/USP, vol. 153 (2 $2^{\circ}$ semestre). São Paulo: Ed. Humanitas, 2005, p. 11-33.

QUIJADA, Mónica. Sobre el origen y difusión del nombre "América Latina" (o una variación heterodoxa en torno al tema de la construcción social de la verdad). 
Revista de Indias, vol. LVIII, n. 214. Espanha: CSIC, 1998.

RÉMOND, René(org.). Por uma história política. Rio de Janeiro: Editora UFRJ, 1996.

SAID, Edward. Representações do intelectual. São Paulo: Companhia das Letras, 2005.

SEVCENKO, Nicolau. Literatura como missão: tensões sociais e criação cultural na Primeira República. $2^{a}$ ed. São Paulo: Companhia das Letras, 2003.

TODOROV, Tzevetan. A conquista da América: a questão do outro. São Paulo: Martins Fontes, 2003.

VASCONCELOS, Francisco de. Câmara Cascudo de Potegí ao Piabanha. Natal; Petrópolis, s./e, 1989.

VENTURA, Roberto. Estilo tropical: História cultural e polêmicas literárias no Brasil 1870-1914. São Paulo: Companhia das Letras, 1991.

\section{Site consultado}

Disponível em: http://www.apcl.com.br/noticias/coluna silviojulio.html Acesso em: 07/09/03

Recebido: setembro/2008 - Aprovado: junho/2009 